\title{
Reliability of Baseload Electricity Generation from Fossil and Renewable Energy Sources
}

\author{
Aleksa Z. Biserčić*, Uglješa S. Bugarić \\ Mechanical Engineering Faculty, University of Belgrade, Belgrade, Serbia \\ Email: *aleksbisercic@gmail.com
}

How to cite this paper: Biserčić, A.Z. and Bugarić, U.S. (2021) Reliability of Baseload Electricity Generation from Fossil and Renewable Energy Sources. Energy and Power Engineering, 13, 190-206. https://doi.org/10.4236/epe.2021.135013

Received: April 18, 2021

Accepted: May 28, 2021

Published: May 31, 2021

Copyright $\odot 2021$ by author(s) and Scientific Research Publishing Inc. This work is licensed under the Creative Commons Attribution International License (CC BY 4.0).

http://creativecommons.org/licenses/by/4.0/

\section{(c) (i) Open Access}

\begin{abstract}
With expanding environmental and climate change regulatory frameworks, the fossil-based baseload generation is forced to decline, thus making room for more and more generation based on renewable and other carbon-free energy sources. This paper deals with a number of controversial issues and open questions concerning the growing penetration of renewable energy sources into power generation systems, often without due care of the impacts of variable as compared to conventional generation on the reliability of electricity supply. Particular attention is paid to baseload generation, power market design, system operation under extreme weather conditions, energy storage, back-up, and reserve power, as well as to the role of mechanical inertia and reliability of on-site fuel supply, demonstrated on an example of coal excavation and delivery to a power plant.
\end{abstract}

\section{Keywords}

Power System, Baseload, RES, Emergencies, Storage, Reliability, On-Site Coal Supply

\section{Introduction}

The world is currently undergoing an unprecedented energy transition, driven by the goal to limit global warming and keep the global temperature raise less than $2^{\circ} \mathrm{C}$. The sources of primary energy for power generation have spontaneously varied over decades. Currently, the non-renewable resources of coal and uranium are principal fuels for electricity generation, owing to their ready availability, mature technology, and relatively low cost of electricity generated. Renewable energy sources (RES), including hydro, geothermal, biomass, solar, and wind have all demonstrated their ability to provide continuous electricity supply, but not yet at the same scale as coal and nuclear. While further developments in 
controllable renewable (hydro, geothermal and biomass) power generation is limited, non-controllable intermittent (wind and solar) generation is projected to expand. However, their fast technological development and lowering the costs suggest that more and more RES can be expected, particularly due to concerns related to global warming and climate change, with a major role played in greenhouse gas (GHG) emissions by coal-fueled power generation.

Coal is the world's most abundant and widely distributed fossil fuel source. Currently, around $27 \%$ of global primary energy needs are met by coal and $42 \%$ of electricity is generated from coal [1]. In coal rich countries like Australia, Poland, Serbia, and many others, much above the world average electricity is generated from coal-fired power stations. As the coal-powered stations have the highest GHG emissions of all power generation technologies, some "clean coal" technologies promise to substantially decrease the level of GHG emissions, but resultant levels would still be about one order of magnitude higher than for renewables [2]. The coal-fired electricity market hopes to survive on the geosequestration of $\mathrm{CO}_{2}$ aimed to conform to the demands of the low-carbon economy, but its commercial feasibility, is yet to be demonstrated, and may prove so costly that the energy cost advantage currently offered by coal relative to renewables is likely to be eroded [3].

On the other hand, provided suitable policy frameworks are in place, there is no technical or financial impediment to renewables to meet electricity demand in the longer term, with gas playing the role of the change agent. The current research and development suggest that there is a lot of potential for major advances in RES technologies over the next few decades and that a low-carbon electricity sector is attainable with total substitution of coal [4]. The decentralized nature of renewable power and the ability to hybridize between different types of RES and with fossil-fuel based back-up systems suggest that RES will dominate in the expansion of electricity supply [5].

Worldwide promotion of the use of VRES has resulted in a continuous growth of their installed capacities and electricity generated with a primary objective to quantitatively replace generation from fossil fuels. However, in an effort to reach the climate goals as soon as possible, qualitative analyses of the impacts of such a transition have been undermined. Therefore, any major change in direction towards RES initiates controversies over several critical issues and still opens up uncertainties concerning their ever raising share in the power generation mix. Whilst some argue that the technical challenges and costs of RES are so great that it is hard to commit to strict deadlines, others point out that the development and implementation of $\mathrm{CO}_{2}$ geo-sequestration and clean coal technologies are not guaranteed and will incur costs which will substantially increase the cost of energy to the consumers [3].

These and other issues are addressed in this paper, with particular attention paid to the specific demands of the power system, ability of RES to provide baseload electricity demand, back-up and reserve power generation, as well as the reliability of fuel supply. The next section (Section 2) is devoted to controversial 
issues about baseload electricity generation from conventional and RES based power plants. Section 3 deals with the energy storage and back-up generation issues with particular focus on system reliability in emergency situations. Section 4 extends this topic to the fuel supply and "on-site" storage challenges, demonstrated on an example of a coal-fired power plant in Serbia with support of statistical analytics of service reliability and related quantification and discussion of the performances.

\section{Controversial Issues on Baseload Generation}

The baseload (also "base-load") on a grid is the minimum level of demand over a defined period of time. Historically, baseload power plants that use non-renewable fuel (coal, uranium, gas, etc.) were built and operated to serve baseload demand. They are expected to reliably provide electricity year-round to recover their high capital costs. However, as it is not optimal for power plants to produce the maximum needed power at all times and with a high capacity factor, flexible power plants have been built typically with moderate capacity factors and used to serve variable portion of the supply curve, while the peaking units are typically built to serve peak load and have low capital costs but high operating costs [1]. Therefore, along with baseload power plants which provide the minimum needed electricity, the remainder of demand, varying throughout a day, is met by flexible generation which can be turned up or down quickly, such as "load following" and "peaking" power plants.

Major changes in the power generation mix have recently included a large growth in variable RES (VRES) wind and solar generation alongside a decline of baseload coal power generation and an increase of more flexible generation from natural gas. Despite claims by many, who see the energy transition as the replacement of fossil energy sources by RES, that baseload power generation is becoming less important with a fast increasing share of RES in total power generation, baseload generation remains of importance in maintaining power system reliabilities and efficiencies [6]. The current level of coal baseload power will likely be further reduced in the future irrespective of promising advances in carbon capture, (use) and storage systems and other technological improvements [7]. However, since other upgrades in power systems are costly and will likely take several decades to develop and install, the electricity supplies and required systems' reliabilities will most likely continue to require certain levels of baseload power generation, well into the second half of this century [1].

The RES are usually criticized as unsuited to provide baseload power because of their intermittency, and further development in the renewables sector is required before any significant level of substitution of coal-based baseload power can take place. Some continue to advocate that there is no inherent need for baseload power, as there is no clear evidence that changing power mix with VRES endangers electric system reliability. The German Advisory Council on the environment claims that the new baseload power plants or the life extension of the existing ones would endanger the development of RES, and would not constitute 
a bridge to the energy supply system of the future [8].

The coal based baseload power will certainly continue to decline, but at a rate and to levels highly dependent on the continued availability of natural gas power, and on its market prices. Also, as the VRES will continue to expand in the future, possible limited availability of natural gas power generation capacities could become a growing problem to the power systems' reliability and generation costs [9]. Further developments in fully-controllable (dispatchable) RES (hydro, geothermal and biomass) power generation will definitely help, but the future of these technologies is uncertain due to numerous economic and environmental constraints [10]. Even so, a huge amount of baseload fossil fuel power will be needed to help renewable energy take its place through producing and installing the RES based power plants and energy storage systems in an attempt to solve the problem of their intermittency.

Dispatchable generation refers to sources of electricity that can be dispatched on demand at the request of power grid operators. The dispatchable power plants that provide spinning reserve (frequency control) and balancing the electric power system (load following) allow generation matching either slow changes in power demand or peak loads [11]. These plants are capable of satisfying the peaks in demand through quick deployment of dispatchable generation. The non-dispatchable RES such as wind power and PV solar power cannot be controlled, and therefore the grids with high penetration of renewable energy sources generally need energy storage and/or dispatchable generation rather than baseload generation [8].

Even though some advocate that VRES capacity can directly displace conventional baseload power plants ([8]), this assumption is not considered adequate since baseload coal power is normally operated continuously at fairly largeconstant generation rates and for extended periods of time, while VRES power generation is a function of uncontrollable time-of-day and weather conditions and requires strong back-up generation, as well as large longer-term energy storages. The natural gas power plants might both displace baseload coal power (known as fuels switching) and enable VRES share to raise in power generation mix.

Contrary to the claims that conventional baseload power plants have to be preserved, there are claims that favorable economics and improved environmental performance of RES technologies like wind, solar, and batteries should prevail [12]. Proponents of RES argue that some RES technologies (hydro, geothermal, biomass) can also supply baseload power, and that intermittency of other sources such as wind and solar photovoltaic (PV) can be addressed by coupling them with peak-load plants such as gas turbines fueled by biofuels or natural gas, which can quickly be switched on to fill in gaps of low wind or solar production [13]. Gas turbine technology, with its lower $\mathrm{CO}_{2}$ emissions, can replace coal-fired power stations and support renewable power plants to ramp up in size and number [2]. In the longer term, it appears that there is no technical limit for RES to supply all needs of electricity provided that cost-effective and re- 
liable energy storage devices are available [4].

From the physics point of view, VRES behave quite differently from the synchronous generators installed in conventional power plants. Namely, synchronous generators have mechanical inertia and are therefore capable of storing kinetic energy in their rotating mass. Moreover, since the terminals of these generators are directly linked with the network, this energy is inherently exchanged with the system during disturbances, which makes the network less prone to frequency fluctuations in case of an imbalance between generation and load. On the other hand, VRES generation units are equipped with power electronic converters which decouple the generators from the grid and thus provide no inertia to the system. As it is projected that many of the conventional power plants will be gradually displaced by the VRES, the total inertia perceived by the system will seriously decrease. The inertia related issues will mainly arise in terms of frequency control as low system inertia results in a high rate of change of frequency values and substantial frequency deviations which can lead to instability of the system including load shedding or even blackouts [14]. Although many solutions (ranging from a simple re-dispatch to a modified control approach for converters) are considered capable to cope with these issues, some kind of conventional mechanical inertia in the system seems inevitable as an important part of the solution.

\section{Energy Storage and Back-Up Generation}

The intermittency issue, mainly represented by wind energy and to a lesser degree solar energy, is commonly cited as the main technical reason that limits the level of RES which can be incorporated into a grid without compromising overall reliability. Whilst this can be offset to some degree by ensuring a wide geographic distribution of renewable generation to decrease the frequency of low supply periods, and by ensuring a variety of RES technology inputs into the grid, the ultimate solution required to deliver the reliability of supply required will be based on storage systems that are able to store intermittent energy when produced and release it on demand.

Therefore, a key solution to replace the coal-powered generation will be the development of such storage media that can capture intermittent energy and supply controlled output to match demand. Conventional pumped storage hydropower is the utility size energy storage system used as an effective means of storing large quantities of potential energy for long term electricity generation, as the best way of balancing supply and demand and support intermittent renewable power generation while ensuring high system reliability [15]. Compressed air energy storage is also a conventional technology much less used than pumped storage. Currently, a variety of promising new technologies for energy storage are under development at the demonstration level. Those concepts among them that offer reliable utility size long term solutions use the surplus electricity to produce hydrogen or other forms of gaseous fuels. 
There is a belief that sustained power system reliability cannot be fully provided by RES with flexible back-ups from gas-fired generation only [9]. This can be only for part of RES that are dispatchable such as hydro, geothermal, biomass and solar thermal power generation, but not for the intermittent wind or solar photovoltaic (PV) generation, as these VRES require increased back-up/reserve continuously. Of course, the share even up to $100 \%$ is theoretically possible as further smart grids and other new technology developments evolve [4]. This would require uninterruptable gas supply from pipelines, because the gas storage at the gas-fired power plant site is not possible such as is the normal practice at coal-fired power plants. However, more back-up power is necessary to protect against conventional plant failures than against renewable energy failures, because, unlike the gradual changes in renewable output, failures at conventional plants occur instantly and abruptly [16].

The proponents of VRES generally overlook the utmost importance of adequate "reserve margins" in enabling power system to sustain required reliabilities. Required "reserve power" totally excludes VRES, which cannot be "dispatched on-demand" as required to properly manage-control short-term power demand changes [11]. In fact, VRES can actually increase the need for added "reserve power" in order to reliably maintain supply-demand balances, depending on the time of day and year, and on weather conditions. Another fact apparently overlooked is that the power systems are required to fully comply with the mandatory regulations on frequency and voltage standards, developed over many years to maintain and improve system reliabilities. Growing share of VRES has also directionally increased the need for reconfiguration of the transmission and distribution networks and high share of "smart grid" technologies, thus increasing the costs of electricity to consumers [17].

The power back-up or reserve power are currently a hot topics on the so called "capacity" market. The open market was considered to be the best way to move away from natural monopolies and offer consumers the possibility to choose their supplier. In general, commodity or service market philosophy plays on supply and demand balancing both supplier and consumer. The reliability of the energy-only market (EOM) in Europe is currently heavily disputed regarding its functionality. The EOM could be extended by a strategic reserve to guarantee the security of supply, but, if the EOM does not work in the long term, a more comprehensive redesign of the electricity market needs to be considered [18]. The introduction of capacity market does not exclude fossil based sources that can be dispatched on-demand when required to properly manage any power demand changes.

The back-up power demonstrated to be of particular concern in emergencies such as caused by extreme weather conditions, either heat waves during summer or freezing temperatures in winter. A recent (mid-February 2021) cold wave left millions of consumers in Texas without electricity for days due to freezing temperatures that caused wind turbines be frozen and natural gas flow be impeded from frozen pipes, and in Germany millions of solar panels blanketed with snow 
and more than 30,000 wind turbines idle due to a lack of wind [19] [20]. This weather event has clearly demonstrated that the market does not provide reliable electricity back-ups for emergency situations such as extreme cold weather that puts many power plants off-line and makes power system unable to serve high demand [19].

Emergency preparedness of the systems with a high penetration of VRES seems to be undermined so far. The above mentioned extreme weather events have raised questions around the future of emergency preparedness, as well as about market structure and regulation within the energy sector. Unlike in the summer months, during winter gas supply is mostly diverted for residential heating, thus decreasing its availability for power plants [21]. The problem is further augmented by the lack of dual-fuel generators that can switch to on-site distillate or fuel oil provided that these available on site of the power plant. Reliability of fuel supply is discussed in details in Section 4 of this paper.

The most extreme planning case with high load/high outages reserves (the "worst-case" scenario) must be considered to involve load shed in the face of extreme winter events, combining extreme outages, low wind, and extreme load peak expectations. Winter storms reveal an emerging reliability challenge for the energy transition. The wind turbine icing during winter, combined with weak wind speeds that reduce wind production, deserves particular attention. Also, the duration of low wind during winter may have a serious impact on the security of electricity supply. It is important to note that low wind in winter presents a different risk than its summer intermittency [22]. The key difference is the long duration of low wind in winter coinciding with weather extremes.

While the historical focus of power system reliability at mild climates was on summer months, driven by the air conditioning demand, in recent years, markets with significant VRES penetration have become concerned with meeting peak "net load" (gross load minus VRES generation). Net load is a critical measure because it represents the share of demand that must be served by nonintermittent resources. In the long-term outlook, the peak net load will shift to winter because the growing solar generation will cut into summer peaks on hot, sunny days, while heating will raise winter electricity demand (heat pumps, etc.) when the solar insolation is relatively poor.

More time and information will be required to fully understand all the factors that contribute to the failures in the electricity supply. But at its core, the key question is how planning processes, market rules, and regulations need to change to ensure that the energy complex is able to cope with rare, extreme weather events particularly as climate change introduces the potential for increased risk for these events. Getting this right will raise in importance as the degree of VRES generation increases and reliance on gas as a bridge fuel to decarbonize the energy sector increases.

Therefore, flexible generation and generation that can sustain for multi-day periods, as well as long-duration storage are critical to winter with low wind. The storage duration is needed for at least one week, while current lithium-ion 
batteries with durations of few hours are wholly inadequate to this task. Several long-duration technologies are in development, but they have a long way to scale and mature. Hydrogen has an important role to play as both flexible generation and long-duration storage, but there are still many challenges to overcome prior to its widespread adoption

The power outages have already triggered warm debates over the current efforts to accelerate energy transition, and indicated that extremes, such as cold weather conditions that can cause stop of wind turbines and make natural gas power plants inoperable when needed to back-up them [19]. Questioned, both in Europe and in the USA, are too quick moves to weather-dependent RES, while shutting down baseload coal and nuclear plants and the choice to limit climate change through renewables which caused utilities to turn back to the fossil fuels that are causing the climate change [23].

As extreme weather is becoming more frequent, the utilities need to consider it when tackling grid resilience strategies. As the climate changes, so too should the infrastructure change become hardier and power utilities preserve all (fossil, nuclear and other zero-carbon) resources [24]. This particularly refers to the reliable fuel supply on power plant sites, such as the common practice at the sites of coal-fired thermal power plants.

\section{Reliability of the On-Site Fuel Supply}

Without exception, no source of electricity runs full time. Conventional baseload plants either periodically experience unexpected outages, or need to be turned off for routine maintenance. The average coal plant is unavailable to supply power about $15 \%$ of the time, while the average nuclear plant and gas plant are unavailable about $9 \%$ and $5 \%$ of the time, respectively [1]. The wind and solar plants are also prone to failures, but have much lower failure rates. Solar panels have only few moving parts and are easily maintained, making their forced outage rate close to zero [16]. Similarly, the forced outage rate of modern wind turbines does not exceed $2 \%$, while the forced outage rate for coal fired power plants is $6 \%$ to $10 \%$, [20]. In other words, renewable resources are more technically available compared to conventional resources, but their variability is reflected in much shorter annual operation.

Reliability of fuel supply tends to be of great concern, both for regular and emergency/back-up power generation [25]. On-site fuel (most often diesel) is typically required for many critical applications. Historically, perceptions of reliability have made diesel the primary fuel of choice for back-up power applications. Whereas diesel generators can operate reliably during extended outages, many issues can impact the reliability of diesel fuel delivery and availability on the site. For example, prolonged exposure to ambient air can cause diesel fuel to oxidize, and ambient temperature changes can lead to condensation and corrosion, leading to hydrocarbon release to the environment [25].

Natural gas is generally more reliable on-site fuel. However, on-site storage of natural gas is not possible, but it is supplied continuously by the infrastructure of 
underground pipelines that are usually not affected by severe weather that can cause electrical power outages. This means that the reliability of supply of natural gas to the power plant is directly related to the reliability of delivery from the gas infrastructure, which, however, is not under control of the power utility [19].

Unlike the liquid and gaseous fuels, solid fuel such as hard coal and lignite, can reliably be stored at the site of power plant in quantities sufficient for continuous electricity generation during and beyond any regular or emergency situation under control of the power utility [26]. Of course, these quantities are optimized taking into account a variety of parameters describing both the internal process of coal supply and use and external circumstances that can have any impact on that process. The coal supply itself appears to be a complex process, particularly when lignite is used as fuel for power generation. Because of its low energy content per unit of mass, lignite is not suitable for long-distance transportation, so that the power plants are usually built close to the mines, where it is continuously excavated, transported to the power plant, prepared and burnt in the steam boilers or stocked for later use. Each of the components of such a chain process contributes its share to the overall reliability of fuel supply, as demonstrated later in this report. Obviously, the more complex process, the more complicated is its reliability metrics.

\subsection{Reliability Metrics}

The reliability metrics are computed through extensive experimentation or experience and the resulting calculations provide understanding of the system reliability and availability and their time dependence. Though reliability and availability are often used interchangeably, they are different concepts in the engineering domain [27]. Reliability is the probability that a system performs correctly during specific time duration. During this correct operation no repair is required or performed as the system adequately follows the defined performance specifications. Availability refers to the probability that a system performs correctly at a specific time instance (not duration) [28]. Interruptions may occur before or after the time instance for which the system's availability is calculated. Availability is measured at its steady state, accounting for potential downtime incidents that can cause a service unavailable during its projected usage duration.

The frequency of component failure per unit time (failure rate, $\lambda$ ) is considered as forecasted failure intensity given that the component is fully operational in its initial condition. The formula for failure rate $\lambda_{r}$ of a repairable component or system is mathematically expressed as:

$$
\lambda_{r}=\frac{1}{M T B F},
$$

where $M T B F$ (Mean Time Between Failures) is the average time duration between inherent failures of a repairable system component. The failure rate of a non-repairable component or system $\lambda_{n}$ is: 


$$
\lambda_{n}=\frac{1}{M T T F},
$$

where MTTF (Mean Time To Fail) is the average time duration before a nonrepairable system component fails.

The frequency of successful repair operations performed on a failed repairable component per unit of time (repair rate, $\mu$ ) is used to calculate the maintenance metrics. Repair rate is defined as:

$$
\mu=\frac{1}{M T T R},
$$

where $M T T R=M T B F-M T T F$ (Mean Time To Repair) is the average time duration to fix a failed component and return to operational state. This maintenance metric includes the time spent during the alert and diagnostic process before repair activities are initiated, but $M T T R$ is the average time solely spent on the repair process and calculated as the ratio of total hours of maintenance and total number of repairs. The MTTR formula is calculated by dividing the total unplanned maintenance time spent on an asset by the total number of failures that asset experienced over a specific period [28]. Obviously, MTTR is dependent on several factors, like the type of plant, its criticality, and particularly its age.

Reliability follows an exponential failure law, which means that it reduces as the time duration considered for reliability calculations elapses. In other words, reliability of a system will be high at its initial state of operation and gradually reduce to its lowest magnitude over time. It is calculated as an exponentially decaying probability function which depends on the failure rate $\lambda$ as follows:

$$
R(t)=\mathrm{e}^{-\lambda \cdot t}
$$

Since failure rate $\lambda$ does not remain constant over the operational lifecycle of a component, the average time-based quantities such as MTTF or MTBF can also be used to calculate reliability [25].

The availability determines the instantaneous performance of a component at any given time based on time duration between its failure and recovery. Availability is calculated as follows:

$$
A(t)=\frac{\mu}{\lambda+\mu}+\frac{\lambda}{\lambda+\mu} \mathrm{e}^{-(\lambda+\mu) \cdot t} .
$$

After a sufficiently long time period, availability reaches its stationary value $A$ :

$$
A=\frac{M T B F}{M T B F+M T T R}=\frac{\mu}{\lambda+\mu} .
$$

Power systems contain multiple components connected as a complex architecture. The effective reliability and availability of the system depend on the specifications of individual components, network configurations, and redundancy models. The configuration can be series, parallel, or a hybrid of series and parallel connections between system components. The effective failure rates are used to compute reliability and availability of the system using these formulae. For $n_{s}$ 
serially connected components, the effective failure rate is determined as the sum of failure rates of each particular component $i$ :

$$
\lambda_{s}=\sum_{i=1}^{n_{s}} \lambda_{i} .
$$

For parallel connected components, $M T B F$ is determined as the reciprocal sum of failure rates of each system component. For $n_{p}$ parallel connected components it is:

$$
M T B F=\sum_{i=1}^{n_{p}} \frac{1}{\lambda_{i}}
$$

The reliability for series of $n_{s}$ connected components is computed as the product of reliability values of individual components as follows:

$$
R_{s}(t)=\prod_{i=1}^{n_{s}} R_{i}(t) .
$$

The availability for series of $n_{s}$ connected components is computed as the product of availability values of all individual components as follows:

$$
A_{s}(t)=\prod_{i=1}^{n_{s}} A_{i}(t)
$$

For parallel connected components, the formulas for reliability and availability are:

$$
R_{p}(t)=1-\prod_{i=1}^{n_{p}}\left[1-R_{p i}(t)\right]
$$

and

$$
A_{p}(t)=1-\prod_{i=1}^{n_{p}}\left[1-A_{p i}(t)\right] .
$$

It can be observed that the reliability and availability of a series-connected network of components are lower than these metrics of individual components and that opposite is true for parallel network model. For the reason of simplicity, a system of serially connected components is selected for the case study on reliability of coal supply to the site of a power plant.

\subsection{The Case Study}

At an open-pit mine, the excavation of lignite from the earth is carried out by specially designed bucket wheel excavators. From there lignite, after separation of impurities, is transported to the site of the power plant. There, coal is crushed and either stocked at the site or directed towards the coal mills where it is pulverized in special mills and fed into the steam boilers where is being burnt. This complex fuel supply system is composed of three serially connected components (excavator-transporter-crusher) as shown in Figure 1.

The case study selected for presentation herewith is based on a detailed evaluation of reliability and availability metrics of the coal supply system of the 


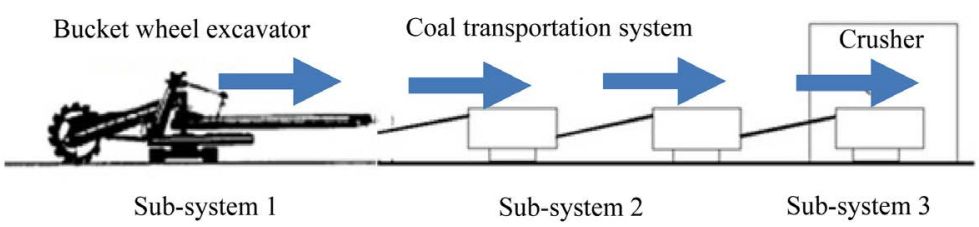

Figure 1. Coal excavation, delivery and preparation system.

Drmno open-pit mine to the Kostolac B thermal power plant in Serbia [29]. Based on the well-established longer-term statistical data, the reliability metrics of the fuel supply system is developed in steps, starting with these metrics specific to electrical, mechanical and other devices of three major components (excavator, transporter and crusher) and then combined for the system as a whole to determine overall reliability of fuel supply to enable continuity of baseload generation.

The bucket wheel excavators (sub-system 1) are expected to operate continuously with high productivity, availability and reliability irrespective of the weather conditions. These metrics are closely related to the reliability of its components as well as to the proper operation and maintenance processes. Based on the three years (2016, 2017 and 2018) long operational data records, the failure rates $\left(\lambda_{b}\right)$ and repair rates $\left(\mu_{b}\right)$ are calculated, classified into three mutually exclusive classes, that take account of the type (electrical, mechanical and other) of components of the excavator, Table 1.

The time dependent reliability of the bucket wheel excavator is calculated by multiplying reliabilities of the electrical, mechanical and other components determined by their failure rates $\lambda_{e}, \lambda_{m}$ and $\lambda_{o}$ respectively. Therefore:

$$
R_{b}(t)=\mathrm{e}^{-\lambda_{e} \cdot t} \cdot \mathrm{e}^{-\lambda_{m} \cdot t} \cdot \mathrm{e}^{-\lambda_{o} \cdot t}=\mathrm{e}^{-\left(\lambda_{e}+\lambda_{m}+\lambda_{o}\right) \cdot t}=\mathrm{e}^{-0.026688066 \cdot t}
$$

where $t$ is the time expressed in hours (h). The time dependent availability $A(t)$ of the excavator is determined from the calculated values of $M T B F$ and $M T T R$, i.e. from its overall rates of failure $\left(\lambda_{b}\right)$ and repair $\left(\mu_{b}\right)$ as follows:

$$
A_{b}(t)=\frac{\mu_{b}}{\lambda_{b}+\mu_{b}}+\frac{\lambda_{b}}{\lambda_{b}+\mu_{b}} \mathrm{e}^{-\left(\lambda_{b}+\mu_{b}\right) \cdot t}=0.9484255+0.0515745 \cdot \mathrm{e}^{-0.5174659 \cdot t}
$$

The stationary value of availability of the bucket wheel excavator is 0.94842563 .

The records from the same data base were used to calculate the failure and repair rates of the electrical, mechanical and other components of the belt conveyor, and therefrom for the overall sub-system 2, Table 2 .

The time dependent reliability of the belt conveyor is calculated by multiplying reliabilities of the electrical, mechanical and other components determined by their failure rates $\lambda_{e}, \lambda_{m}$ and $\lambda_{o}$ respectively.

$$
R_{t}(t)=\mathrm{e}^{-\lambda_{e} \cdot t} \cdot \mathrm{e}^{-\lambda_{m} \cdot t} \cdot \mathrm{e}^{-\lambda_{o} \cdot t}=\mathrm{e}^{-\left(\lambda_{e}+\lambda_{m}+\lambda_{o}\right) \cdot t}=\mathrm{e}^{-0.0823098 \cdot t}
$$

The time dependent availability $A(t)$ of the belt conveyor is determined from the calculated values of $M T B F$ and $M T T R$, i.e. from its overall rates of failure $\left(\lambda_{t}\right)$ and repair $\left(\mu_{t}\right)$ as follows: 
Table 1. Failure and repair rates of the bucket wheel excavator.

\begin{tabular}{ccccc}
\hline Type of component & Electrical & Mechanical & Other & Sub-system 1 \\
\hline Failure rate $\left(\lambda_{b}\right), \mathrm{h}^{-1}$ & 0.011271174 & 0.008464176 & 0.006952716 & 0.026688066 \\
Repair rate $\left(\mu_{b}\right), \mathrm{h}^{-1}$ & 0.598852773 & 0.834782609 & 0.273587611 & 0.490777867 \\
\hline
\end{tabular}

Table 2. Failure and repair rates of the belt conveyor (Sub-system 2).

\begin{tabular}{ccccc}
\hline Type of component & Electrical & Mechanical & Other & Sub-system 2 \\
\hline Failure rate $\left(\lambda_{b}\right), \mathrm{h}^{-1}$ & 0.024312918 & 0.042666360 & 0.015330522 & 0.082309801 \\
Repair rate $\left(\mu_{b}\right), \mathrm{h}^{-1}$ & 1.280432822 & 1.868362832 & 0.827586207 & 1.489821563 \\
\hline & & & \\
$A_{t}(t)=\frac{\mu_{t}}{\lambda_{t}+\mu_{t}}+\frac{\lambda_{t}}{\lambda_{t}+\mu_{t}} \mathrm{e}^{-\left(\lambda_{t}+\mu_{t}\right) \cdot t}=0.9331501+0.0515745 \cdot \mathrm{e}^{-1.2312621 \cdot t}$ & $(12 \mathrm{~b})$
\end{tabular}

The stationary value of availability 0.9331501 of the sub-system 2 is reached before 50 hours.

Finally, the calculated failure and repair rates for the sub-system 3 (crumbler) are $0.0525124 \mathrm{~h}^{-1}$ and $0.6642935 \mathrm{~h}^{-1}$ respectively. The Equations (11c) and (12c) have been developed for the reliability and availability calculation of the crumbler facility (Sub-system 3). The stationary value of availability of the sub-system 3 is 0.9267411 thanks to well organized maintenance and spare parts supply services.

$$
\begin{gathered}
R_{c}(t)=\mathrm{e}^{-\lambda_{e} \cdot t} \cdot \mathrm{e}^{-\lambda_{m} \cdot t} \cdot \mathrm{e}^{-\lambda_{o} \cdot t}=\mathrm{e}^{-\left(\lambda_{e}+\lambda_{m}+\lambda_{o}\right) \cdot t}=\mathrm{e}^{-0.0525124 \cdot t} \\
A_{c}(t)=\frac{\mu_{c}}{\lambda_{c}+\mu_{c}}+\frac{\lambda_{c}}{\lambda_{c}+\mu_{c}} \mathrm{e}^{-\left(\lambda_{c}+\mu_{c}\right) \cdot t}=0.9267411+0.0732519 \cdot \mathrm{e}^{-0.7168059 \cdot t}
\end{gathered}
$$

Time dependent values of reliability and availavility of the sub-systems 1 (bucket wheel excavator), 2 (belt conveyor) and 3 (crusher) are compared in Figure 2. Evidently, reliability of the sub-system 2 falls fast, reflecting the fact that it comprises three long serially connected belt conveyors. Due to extremely hard working conditions, availability of the sub-system 3 (crusher) is somewhat lower than of the other two.

Because the three sub-systems are independent and serially connected, the Equations (7) and (8) are applicable to calculate the overall reliability and availability of the whole system employed to continuously deliver coal to the site of the Kostolac B power plant. Their time dependent values are presented in Figure 3.

Due to the extreme complexity of the coal supply system, and serial connection of its components, its reliability falls rather fast, which indicates the need for well organised continuous maintenance services. These services prove to be effective, resulting in an over $82 \%$ availability, which means that the system is out of service less than $18 \%$ of the time between two planned outages for regular overhauls. Nevertheless, the availability of coal is additionally augmented (maximised to $100 \%$ ) by an adequate quantity of coal safely stored on the power plant's site, which is not the case with other fossil fuels or with the RES [30]. 


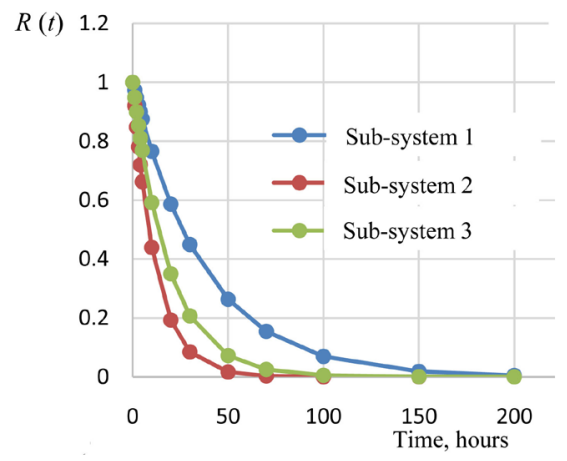

(a)

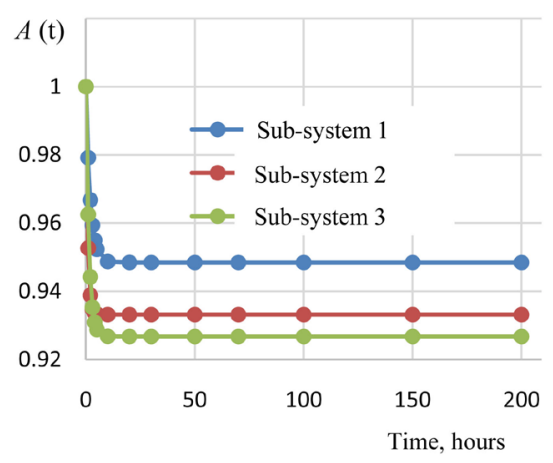

(b)

Figure 2. Time dependent values of reliability (a) and availability (b) of the sub-systems.

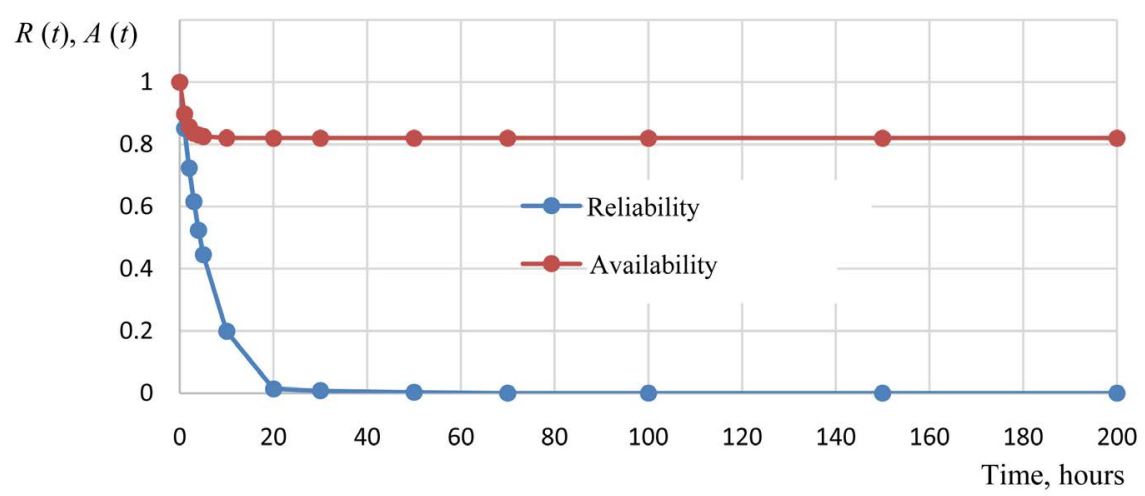

Figure 3. Time dependent values of reliability and availability of the coal supply system.

\section{Conclusions}

To achieve climate change mitigation goals, the fossil based power generation is forced to decline, thus making room for a fast increase of generation based on renewable and other carbon-free energy sources. While further developments in fully dispatchable renewable (hydro, geothermal, and biomass) power generation is limited, non-dispatchable intermittent wind and solar generation is projected to expand. However, the possibility of this non-dispatchable generation to supply baseload electricity is often questioned as compared to fossil-fired baseload generation in terms of reliability, system disturbances, energy storage, inertia, emergency preparedness, and some uncertainties that may appear during transition.

Unlike other fossil fuels, the possibility of safe long-term storage of coal on site of the power plant makes it the most reliable source for baseload electricity generation, particularly in extreme weather conditions. Tracking the reliability of the coal supply to the power plant is a challenge that maintenance services face daily. The reliability metrics of the coal excavation, transportation, and the preparation makes it essential to eliminate guesswork and manage maintenance, as well as to optimize the quantity of coal stored on the site of the power plant for normal and emergency operation. The on-site storage makes coal-fired generation more reliable than achieved by any other fossil fuel, and superior to renewables with gas back-up. 


\section{Conflicts of Interest}

The authors declare no conflicts of interest regarding the publication of this paper.

\section{References}

[1] Needham, S. (2009) The Potential for Renewable Energy to Provide Baseload Power in Australia. Research Paper No. 9, Parliamentary Library Research Publications, Canbera. https://www.aph.gov.au

[2] Ross, K. (2020) How Will Europe Tackle Its Coal Conundrum? Power Engineering International, No. 5, 28-31.

[3] Hammond, G.P. and Spargo, J. (2014) The Prospects for Coal-Fired Power Plants with Carbon Capture and Storage: A UK Perspective. Energy Conversion and Management, 86, 476-489. https://doi.org/10.1016/j.enconman.2014.05.030

[4] Azzuni, A., Aghahosseini, A., Ram, M., Bogdanov, D., Caldera, U. and Breyer, C. (2020) Energy Security Analysis for a 100\% Renewable Energy Transition in Jordan by 2050. Sustainability, 12, Article No. 4921. https://doi.org/10.3390/su12124921 http://www.mdpi.com/journal/sustainability

[5] Gielena, D., Boshella, F., Sayginb, D., Morgan D. Bazilianc, M.D., Wagnera, N. and Gorinia, R. (2019) The Role of Renewable Energy in the Global Energy Transformation. Energy Strategy Reviews, 24, 38-50. https://doi.org/10.1016/j.esr.2019.01.006

[6] Caldecott, B., Tulloch, D.J., Bouveret, G., Pfeiffer, A., Kruitwagen, L., McDaniels, J. and Dericks, G. (2017) The Fate of European Coal-Fired Power Stations Planned in the Mid-2000s: Insights for Policymakers, Companies, and Investors Considering New Coal. Working Paper, Sustainable Finance Programme, Oxford. https://doi.org/10.2139/ssrn.3019030

[7] Morton, A. (2020) More Coal Power Generation Closed than Opened around the World This Year, Research Finds. The Guardian.

[8] Schmidt, J. (2010) Renews Special: Renewable Energies and Baseload Power Plants: Are They Compatible? No. 35, German Renewable Energies Agency, Berlin.

[9] Martinez Romero, S. and Hughes, W. (2015) Bringing Variable Renewable Energy up to Scale Options for Grid Integration Using Natural Gas and Energy Storage. Technical Report 00 6/15, the International Bank for Reconstruction and Development, the World Bank Group, Energy Sector Management Assistance Program (ESMAP), Washington DC.

[10] Mesarović, M. (2001) Sustainable Energy from Biomass. Thermal Science, 5, 5-32.

[11] Lovegrove, K., James, G., Leitch, D., Milczarek, A., Ngo, A., Rutovitz, J., Watt, M. and Wyder, J. (2018) Comparison of Dispatchable Renewable Electricity Options. In: Lovegrove, K., Rutovitz, J., James, G., Watt, M., Leitch, D., Wyder, J. and Ngo, A., Eds., Technologies for an Orderly Transition, Australian Renewable Energy Agency, Canbera, 104-130.

[12] International Renewable Energy Agency (2017) Electricity Storage and Renewables: Costs and Markets to 2030. International Renewable Energy Agency, Abu Dhabi. http://www.irena.org/publications

[13] International Renewable Energy Agency (2018) Global Energy Transformation: A Roadmap to 2050. International Renewable Energy Agency, Abu Dhabi. http://www.irena.org/publications

[14] Tielens, P., Henneaux, P. and Cole, S. (2018) ASSET Study on Penetration of Rene- 
wables and Reduction of Synchronous Inertia in the European Power SystemAnalysis and Solutions. European Commission, Directorate-General for Energy and Directorate for Internal Energy Market, Brussels.

[15] Breeze, P. (2018) Pumped Storage Hydropower. In: Breeze, P., Ed., Hydropower, Academic Press, Cambridge, 73-78.

https://doi.org/10.1016/B978-0-12-812906-7.00008-9

[16] Sayed, A., El-Shimy, M., El-Metwally, M. and Elshahed, M. (2019) Reliability, Availability and Maintainability Analysis for Grid-Connected Solar Photovoltaic Systems. Energies, 12, Article No. 1213. http://www.mdpi.com/journal/energies https://doi.org/10.3390/en12071213

[17] Buti, M., Verwey, M. and Buder, A. (2015) Energy Economic Developments, Investment perspectives in electricity markets. Institutional Paper 003. Publications Office of the European Union, Luxembourg, 2443-8014 (online).

[18] Renz, L., Hartel, R., Keles, D., Fichtner, W and Keko, H. (2017) Case Study: Design Options for the German Electricity Market. In: Welsch, M., Pye, S., Howells, M., et al., Eds., Europe's Energy Transition-Insights for Policy Making, Academic Press, Cambridge, 131-139. https://doi.org/10.1016/B978-0-12-809806-6.00018-3

[19] Douglas, E. (2021) Texas Largely Relies on Natural Gas for Power: It Wasn't Ready for the Extreme Cold. The Texas Tribune.

[20] Patel, S. (2021) Fending off Forced Power Plant Outages. Power Magazine.

[21] Sweezey, R. (2021) Winter Reliability and the Road to Net Zero. https://www.woodmac.com/reports/gas-markets-winter-storm-uri-reveals-an-emer ging-winter-reliability-challenge-for-the-energy-transition-485755

[22] Ravestein, P., van der Schrier, G., Haarsma, R., Scheele, R. and van den Broek, M. (2018) Vulnerability of European Intermittent Renewable Energy Supply to Climate Change and Climate Variability. Renewable and Sustainable Energy Reviews, 97, 497-508. https://doi.org/10.1016/j.rser.2018.08.057

[23] Callaway, L. and Davis, M. (2021) Is Renewable Energy a Threat to Grid Resilience? Transmission and Distribution World.

[24] Largue, P. (2021) Op-Ed: Fossil Fuels versus Renewables as Global Temperatures Plummet. Power Engineering International.

[25] Lovins, A. (2017) Does "Fuel On Hand" Make Coal and Nuclear Power Plants More Valuable? Forbes.

[26] U.S. Environmental Protection Agency (2016) Investigation of Corrosion-Influencing Factors in Underground Storage Tanks with Diesel Service. EPA 510-R-16-001, U.S. Environmental Protection Agency, Office of Underground Storage Tanks, Washington DC.

[27] North American Electric Reliability Corporation (2020) Reliability Guideline: Fuel Assurance and Fuel Related Risk Analysis for the Bulk Power System. North American Electric Reliability Corporation, Atlanta.

[28] Large, D. and, Farmer, J. (2009) Network Reliability and Availability. In: Large, D. and Farmer, J., Eds., Broadband Cable Access Networks, Morgan Kaufmann, Burlington, 347-376. https://doi.org/10.1016/B978-0-12-374401-2.00012-7

[29] Bugarić, U., Tanasijević, M., Gomilanović, M., Petrović, A. and Ilić, M. (2020) Analytical Determination of Availability of Rotary Excavator as a Part of Coal Mining System-Case Study: Rotary Excavator SchRs 800.15/1.5 of the Drmno Open Pit Mine. Mining and Metallurgy Engineering Bor, No. 3-4, 25-36.

[30] Bergman, A., Denholm, P. and Steinberg, D.C. (2016) Maintaining Reliability in the Modern Power System. US Department of Energy (DOE), Washington DC. 


\section{Nomenclature}

Symbols

A

$R \quad$ Reliability (-)

$\lambda \quad$ Failure rate $\left(\mathrm{h}^{-1}\right)$

$\mu \quad$ Repair rate $\left(\mathrm{h}^{-1}\right)$

$t \quad$ Time (h)

$n \quad$ Number of components (-)

\section{Subscripts}

n

Non-repairable

$p \quad$ Parallel

$r \quad$ Repairable

$s \quad$ Serial

$b \quad$ Bucket wheel excavator

c Coal crusher

e Electrical

m Mechanical

$o \quad$ Miscellaneous

$t \quad$ Belt conveyor 